\title{
is Research Soure \\ Epidemiology of chemical poisoning among adults in Qassim region: An eight years study
}

\section{Sulaiman Alnasser ( $\sim$ sm.alnasser@qu.edu.sa )}

Qassim University

\author{
Research Article \\ Keywords: Adults, Chemical poisoning, Saudi Arabia
}

Posted Date: March 17th, 2021

DOI: https://doi.org/10.21203/rs.3.rs-309582/v1

License: (c) (i) This work is licensed under a Creative Commons Attribution 4.0 International License. Read Full License 


\section{Abstract \\ Background}

Chemical poisoning is considered a common medico-social problem that, in addition to causing extensive morbidity and mortality, dominates the valuable health care service resources.

\section{Objective}

This study was conducted to explore the extent and frequency of chemical poisoning events among adults in Qassim region as well as the most common poisoning agents involved.

\section{Methods}

This is a retrospective study employing medical record review for chemical poisoning cases that occurred in Qassim region during the 8-year period from January 2008 to December 2015. Data was collected using a standardized, validated data collection sheet.

\section{Results}

There is no steady trend (either decreasing or increasing) of the number of poisoning cases through time. There is statistically significant association between the type of poisoning agent and gender $\left(\chi^{2}=14.3104, P<0.05\right)$. Also, there is statistically significant association between the type of poisoning agent and period in years $\left(\chi^{2}=19.7565, P<0.05\right)$.

\section{Conclusions}

Most cases of poisoning affected female, with no pattern through time. Educational programs are needed to raise public awareness about poisoning, especially among women.

\section{Introduction}

Any substance that can harm living beings as a result of absorption into the body following contact with the skin or after ingestion is known as a poison. Poisonous materials that cross the placenta can affect fetus as well. Many substances can act as poisons if a sufficiently large dose is absorbed (WHO, 2017). These poisons result in chemical actions which are capable of producing injury or dysfunction in the body (Z'Gambo et al., 2016; Oraie et al., 2017). It is documented that poisoning represents a significant global public health challenge in terms of morbidity and mortality to the extent that it is considered the second largest cause of morbidity worldwide, following road traffic accidents (Z'Gambo et al., 2016). Therefore, poisoning is considered a common medico-social issue that, in addition to causing extensive morbidity and mortality, dominates the valuable health care service resources (Howlader et al., 2008). Estimations attribute more than 340,000 unintentional deaths to poisoning which can result in loss of more than 7.4 million years of healthy life globally (disability adjusted life years, DALYs) (Z'Gambo et al., 2016). In addition to unintentional, estimation of intentional poisoning cases gives a number of about 2 million per year, causing an approximate 200,000 associated deaths (Chala et al., 2015). 
However, in spite of all that, poisoning is still considered as a neglected problem (Ali et al., 2017). This has resulted in that few researches investigated this problem, leading to inadequate available epidemiological data, especially in developing countries including Saudi Arabia. Consequently the exact extent and complication of the problem is not known. Therefore, this study was conducted to explore the extent and frequency of chemical poisoning events among adults in Qassim region as well as the most common poisoning agents involved to fill this literature gap, especially in Saudi Arabia, as it is essential for well-planned intervention to mitigate the problem to have a clear picture about the nature and magnitude of the problem.

\section{Methods}

This study was a retrospective review of chemical poisoning cases that occurred during the 8-year period from January 2008 to December 2015. The cases were reported to the Food and Chemical Safety Program, Environmental and Occupational Health Directorate, General Directorate of Public Health, Ministry of Health (MOH), Saudi Arabia as part of a national program of food, drug and chemical safety. The purpose of the program is to record the adverse effects of food, drug and chemical poisoning cases on humans during production, storage, transport and use. The reporting system is mandatory for each poisoning case by all health care providers. All cases are saved in Microsoft Excel. The study was approved by the Ministry of Health. Approval was also obtained from the Research Unit, Unaizah College of Pharmacy, Qassim University. A data collection sheet constructed by the consultant of the program (the first author) was used to record personal and socio-demographic information poison category (detergents, disinfectants, insecticides and pesticides, fuels, others), and date of the incident.

Data was analyzed by SPSS software version 20. Descriptive statistics were generated as simple frequency tables and figures. For inferential statistics, chi-square tests were used to compare categorical variables. Statistical significance was set at $\mathrm{P}<0.05$.

\section{Results}

During the period from January 2008 to December 2015, 381 poisoning cases were reported to the Environmental and Occupational Health Directorate, Riyadh after being admitted to hospitals as a consequence of a poisoning event. The highest number of poisoning cases was reported during the period 2011-2013. However, no steady trend (either decreasing or increasing) of the number of poisoning cases could be reported through time. Instead, the trend is zigzagging up and down as can be shown in Fig. 1 below.

Results revealed statistically significant associations between the type of poisoning agent and gender (c2 = 14.3104, $\mathrm{p}$ $<0.05)$. The rate of poisoning by antiseptic and disinfectant among females $(16.8 \%)$ was about three fold the rate among males (5.6\%). On the other hand, the rate of poisoning cleansing substances among males $(14.7 \%)$ was more than double the rate among females (7.0\%). Details of the findings of associations between frequency and type of poisoning agent and gender were presented in Table 1 below. 
Table 1

Relationship between gender and frequency and type of poison ingested

\begin{tabular}{|c|c|c|c|c|c|c|c|c|c|}
\hline \multicolumn{3}{|c|}{ Variables } & \multicolumn{5}{|c|}{ Poisoning Agent } & \multirow[t]{2}{*}{ Total } & \multirow{2}{*}{$\begin{array}{l}x^{2} \\
\text { (p) }\end{array}$} \\
\hline & & & $\begin{array}{l}\text { Antiseptic \& } \\
\text { Disinfectant }\end{array}$ & Fuel & Insecticide & $\begin{array}{l}\text { Cleansing } \\
\text { Substance }\end{array}$ & Other & & \\
\hline \multirow[t]{4}{*}{ Gender } & Male & Count & 8 & 11 & 21 & 7 & 10 & 57 & \multirow{4}{*}{$\begin{array}{l}14.3104 \\
(<0.05)\end{array}$} \\
\hline & & $\begin{array}{l}\% \text { within } \\
\text { Poisoning } \\
\text { Agent }\end{array}$ & 14.04 & 12.28 & 19.30 & 36.84 & 17.54 & 100.00 & \\
\hline & Female & Count & 10 & 11 & 18 & 24 & 23 & 86 & \\
\hline & & $\begin{array}{l}\% \text { within } \\
\text { Poisoning } \\
\text { Agent }\end{array}$ & 27.91 & 12.79 & 20.93 & 11.63 & 26.74 & 100.00 & \\
\hline \multirow{2}{*}{\multicolumn{2}{|c|}{ Total }} & Count & 18 & 22 & 39 & 31 & 33 & 143 & \\
\hline & & $\begin{array}{l}\text { \% within } \\
\text { Poisoning } \\
\text { Agent }\end{array}$ & 22.38 & 12.59 & 20.28 & 21.68 & 23.08 & 100.00 & \\
\hline
\end{tabular}

Also statistically significant associations $(c 2=19.7565, \mathrm{p}<0.05)$ between the type of poisoning agent and period in years were shown. Number of poisoning cases due to antiseptic and disinfectant were the highest in the years 20142015 and 2011-2013 (15 and 12 respectively), while the highest number of poisoning cases (14 cases) in the years 2008-2010 was due to insecticide agents. Details of the findings of associations between frequency and type of poisoning agent and period were presented in Table 2 below.

Table 2

Relationship between time period and frequency and type of poison ingested

\begin{tabular}{|c|c|c|c|c|c|c|c|c|c|}
\hline \multirow[t]{2}{*}{ Variables } & & & \multicolumn{5}{|c|}{ Poisoning Agent } & \multirow[t]{2}{*}{ Total } & \multirow{2}{*}{$\begin{array}{l}x^{2} \\
(p)\end{array}$} \\
\hline & & & $\begin{array}{l}\text { Antiseptic \& } \\
\text { Disinfectant }\end{array}$ & Fuel & Insecticide & $\begin{array}{l}\text { Cleansing } \\
\text { Substance }\end{array}$ & Other & & \\
\hline \multirow[t]{6}{*}{ Duration } & \multirow{2}{*}{$\begin{array}{l}2008- \\
2010\end{array}$} & Count & 2 & 7 & 14 & 11 & 6 & 40 & \multirow{6}{*}{$\begin{array}{l}19.7565 \\
(<0.05)\end{array}$} \\
\hline & & $\begin{array}{l}\text { \% within } \\
\text { Poisoning } \\
\text { Agent }\end{array}$ & 12.50 & 17.50 & 35.00 & 20.00 & 15.00 & 100 & \\
\hline & \multirow{2}{*}{$\begin{array}{l}2011- \\
2013\end{array}$} & Count & 7 & 9 & 15 & 12 & 21 & 64 & \\
\hline & & $\begin{array}{l}\text { \% within } \\
\text { Poisoning } \\
\text { Agent }\end{array}$ & 21.05 & 8.77 & 14.04 & 19.30 & 36.84 & 100 & \\
\hline & \multirow{2}{*}{$\begin{array}{l}2014- \\
2015\end{array}$} & Count & 9 & 6 & 10 & 8 & 6 & 39 & \\
\hline & & $\begin{array}{l}\% \text { within } \\
\text { Poisoning } \\
\text { Agent }\end{array}$ & 32.61 & 13.04 & 15.22 & 26.09 & 13.04 & 100 & \\
\hline \multirow[t]{2}{*}{ Total } & & Count & 18 & 22 & 39 & 31 & 33 & 143 & \\
\hline & & $\begin{array}{l}\% \text { within } \\
\text { Poisoning } \\
\text { Agent }\end{array}$ & 22.38 & 12.59 & 20.28 & 21.68 & 23.08 & 100 & \\
\hline
\end{tabular}




\section{Discussion}

Despite the many health statistics collected from the community in Qassim province, scarce information is available about the frequency of poisoning cases and type of poisoning agents involved. Consequently, no formal registry exists to document this important information. This is one of the reason that encouraged Environmental and Occupational Health Directorate, Riyadh to exploit admissions to casualty departments and hospital wards as a tool for collection and documentation of such important missing information.

Results of this study showed that insecticides followed by detergents, fuel, and then antiseptic and disinfectants were the most common agents of chemical poisoning in Qassim region. Similar findings were reported from Nepal (Singh and Aacharya, 2007), Al Majmaah (Abd-Elhaleem and Muqhem, 2014), India (Nair and Revi, 2015), Zambia (Z'Gambo et al., 2016), and China (Wang et al., 2018). This agreement in literature about most common chemical poisoning agents seems logical as exposure with these toxic materials increased due to increased development in the industrial and agricultural field that had led to wider availability of insecticides (Das, 2007).

Literature reported rising trend in the number of incidences of chemical poisoning generally, and pesticides poisoning in specific. Previous studies estimated the number of deaths due to toxicities caused by pesticides and natural toxins to be about 500,000 per year. Up to half of these poisoning events caused by pesticides occurred in the developing countries despite the fact that these countries account for only $15 \%$ of the worldwide use of pesticides (Dash, 2005). This clearly highlights the weak awareness about handling of these poisoning agents among communities of developing countries. Previous studies conducted in Saudi Arabia and elsewhere highlighted the same (Alanazi, et al., 2018; Jung et al., 2018).

In contradiction with the results of this study, a researcher from Makkah (Hegazy et al., 2012) reported that detergents were the most common poisonous agents. These inconsistencies may be attributed to socio-economic differences. May be pesticides and insecticides are the most common poisoning agents in our study because of the agriculturallybased populations. These results support pervious literature claiming that chemical intoxication demonstrates geographical variations and also influenced by socio-economic level of the society (Abd-Elhaleem and Muqhem, 2014).

The study also revealed a statistically significant association between gender and type of poisoning. A slight predominance in the number of poisoning cases was observed among females compared with males. This contradicts findings obtained from an Indian tertiary care hospital (Mittal et al., 2013). Also a recent study conducted in Jeddah, Saudi Arabia contradict finding from this study (Almuntashiri et al., 2020). However, the current finding of this study had support from several studies conducted in the National Guard Hospital in Jeddah (Bakhaidar et al., 2015), AlQassim (Moazzam et al., 2009), Riyadh (Al-Barraq and Farahat, 2011), India (Hegazy et al., 2012), and Malaysia (Fathelrahman et al., 2005) reported a higher rate among females. It was also noticed that females were more prone to being poisoned by antiseptics and disinfectants. On the other hand, males were more vulnerable to fuel and other poisonous agents. This could be attributed to the fact that women in Qassim spend most of their time at home with families, making them more prone to indoor chemical poisoning. On the other hand, males of working age tend to spend most of their time in outdoor activities, making them more vulnerable to other types of chemical substances like fuel. Findings similar to those obtained from this study were also reported in other local, as well as international studies (Hegazy et al., 2012; Abd-Elhaleem and Muqhem, 2014; Z'Gambo et al., 2016).

Findings of this study also revealed significant associations between types of poisoning agents involved in poisoning cases and the period years included in the study. However, this finding, not only has no support from previous literature, but moreover, contradict some other studies (Oraie et al., 2017). In addition, as no steady trend can be observed, it is 
difficult to attribute these fluctuations up and down in the number of cases for each type of poisoning agent to changes in lifestyle or social behaviour of the society through time.

The main limitation of our study is that not all information was reported to the program. We were unable to measure certain key statistics including; hospitalization rate and duration, specific poisoning antidotes, specific place where the poisoning occurred, and employment of patients which were not reported to the program.

\section{Conclusion}

In conclusion, most cases of poisoning affected female with no pattern through time. Our results indicate that more educational programs are needed to increase awareness of public about chemical poisoning and their effects. These programs can be delivered through mass media or in shopping malls as most of the customers of these shopping malls are females. Such programs need to focus specifically on recommendations for suitable ways of storing chemical products.

\section{Declarations}

\section{Funding}

This study had received no fund

\section{Conflicts of interest/Competing interests}

Nothing to declare

\section{Authors' contributions}

We declare that this work was done by the authors named in this article. Sulaiman Mohammed Alnasser is the principal investigator of the study, and he planned for the first draft of the manuscript and formatted according to the journal requirement. All authors participated in the design of the study and critically reviewed the draft of the manuscript.

\section{References}

Abd-Elhaleem ZAE, Muqhem BAA (2014). Pattern of acute poisoning in Al Majmaah region, Saudi Arabia. AJCEM. 2:7985.

Alanazi MM, AlShammari TH, Alshehri MM, AlShammari TH, Alaradi AA, Alsagre SN, Alrumeh HS, Alqahtani MS (2018). Futures and the outcome of treatment of poisoned children and adolescents admitted to emergency units in different areas of Saudi Arabia. Egypt. J. Hosp. Med. 73:5970-5975.

Al-Barraq A, Farahat F (2011). Pattern and determinants of poisoning in a teaching hospital in Riyadh, Saudi Arabia. Saudi Pharm J. 19:57-63.

Ali I, Sawlani KK, Himanshu D, Chaudhary SC, Usman K, Atam V, Mohd PK (2017). Study of pattern and outcome of acute poisoning cases at tertiary care hospital in north India. J Evid Based Med Healthc. 4:2349-2570.

Almuntashiri N, Alsahafi O, Gamaruddin M, Hammad SA, Tobaiqy M (2020). Assessment of Adverse Events Reported to The Poison Control and Forensic Chemistry Center in Jeddah, Saudi Arabia. medRxiv. 
Bakhaidar M, Jan S, Farahat F, Attar A, Alsaywid B, Abuznadah W (2015). Pattern of drug overdose and chemical poisoning among patients attending an emergency department, western Saudi Arabia. J Community Health. 40:57-61.

Chala TS, Gebramariam H, Hussen M (2015). Two-year epidemiologic pattern of acute pharmaceutical and chemical poisoning cases admitted to Adama Hospital Medical College, Adama, Ethiopia. Asia Pac J Med Toxicol. 4:106-111.

Das RK (2007). Epidemiology of Insecticide poisoining at AlIMS Emergency Services and role of its detection by gas liquid chromatography in diagnosis. Medico-Legal Update. 7:49-60.

Dash SK, Sitarama Raju A, Mohanty MK, Patnaik KK, Mohanty S (2005). Sociodemographic profile of poisoning cases. J Indian Acad Forensic Med. 27:133-138.

Fathelrahman Al, Ab Rahman AF, Mohd Zain Z (2005). MS 04-044: demographic features of drug and chemical poisoning in northern Malaysia. Clin Toxicol. 43:89-94.

Hegazy R, Almalki WH, Afify RH (2012). Pattern of acute poisoning in Makkah region Saudi Arabia. EJCM. 30:1-25.

Howlader MA, Sardar MH, Amin MR, Morshed MG, Islam MS, Uddin MZ, Azhar MA (2008). Clinico-epidemiological pattern of poisoning in a tertiary level hospital. J Dhaka Med Coll. 17:111-115.

Jung WJ, Yu MH, Lee Y, Kim H, Cha YS, Park KH (2018). Relative risk and clinical severity assessment in patients with non-oral route organophosphate poisoning compared with oral route poisoning. Yonsei Med J. 59:982-988.

Mittal N, Shafiq N, Bhalla A, Pandhi P, Malhotra S (2013). A prospective observational study on different poisoning cases and their outcomes in a tertiary care hospital. SAGE Open Med. DOI: 1:2050312113504213.

Moazzam M, Al-Saigul AM, Naguib M, Al Alfi MA (2009). Pattern of acute poisoning in Al-Qassim region: a surveillance report from Saudi Arabia, 1999-2003. East Mediterr Health J. 15:1005-1010.

Nair PK, Revi NG (2015). One-Year Study on Pattern of Acute Pharmaceutical and Chemical Poisoning Cases Admitted to a Tertiary Care Hospital in Thrissur, India. Asia Pac J Med Toxicol. 4:79-82.

Oraie M, Hosseini MJ, Islambulchilar M, Hosseini SH, Ahadi-Barzoki M, Sadr H, Yaghoubi H (2017). A study of acute poisoning cases admitted to the University Hospital Emergency Department in Tabriz, Iran. Drug Res (Stuttg). 67:183188.

Singh DP, Aacharya RP (2007). Pattern of poisoning cases in Bir Hospital. Journal of Institute of Medicine. 28:3-6.

Wang L, Wu Y, Yin P, Cheng P, Liu Y, Schwebel DC, Qi J, Ning P, Liu J, Cheng X, Zhou M (2018). Poisoning deaths in China, 2006-2016. Bull World Health Organ. 96:314.

WHO. (2017). World Health Organization. Poisoning. http://www.who.int/topics/poisons/en/

Z'Gambo J, Siulapwa Y, Michelo C (2016). Pattern of acute poisoning at two urban referral hospitals in Lusaka, Zambia. BMC Emerg Med. 16:2.

\section{Figures}




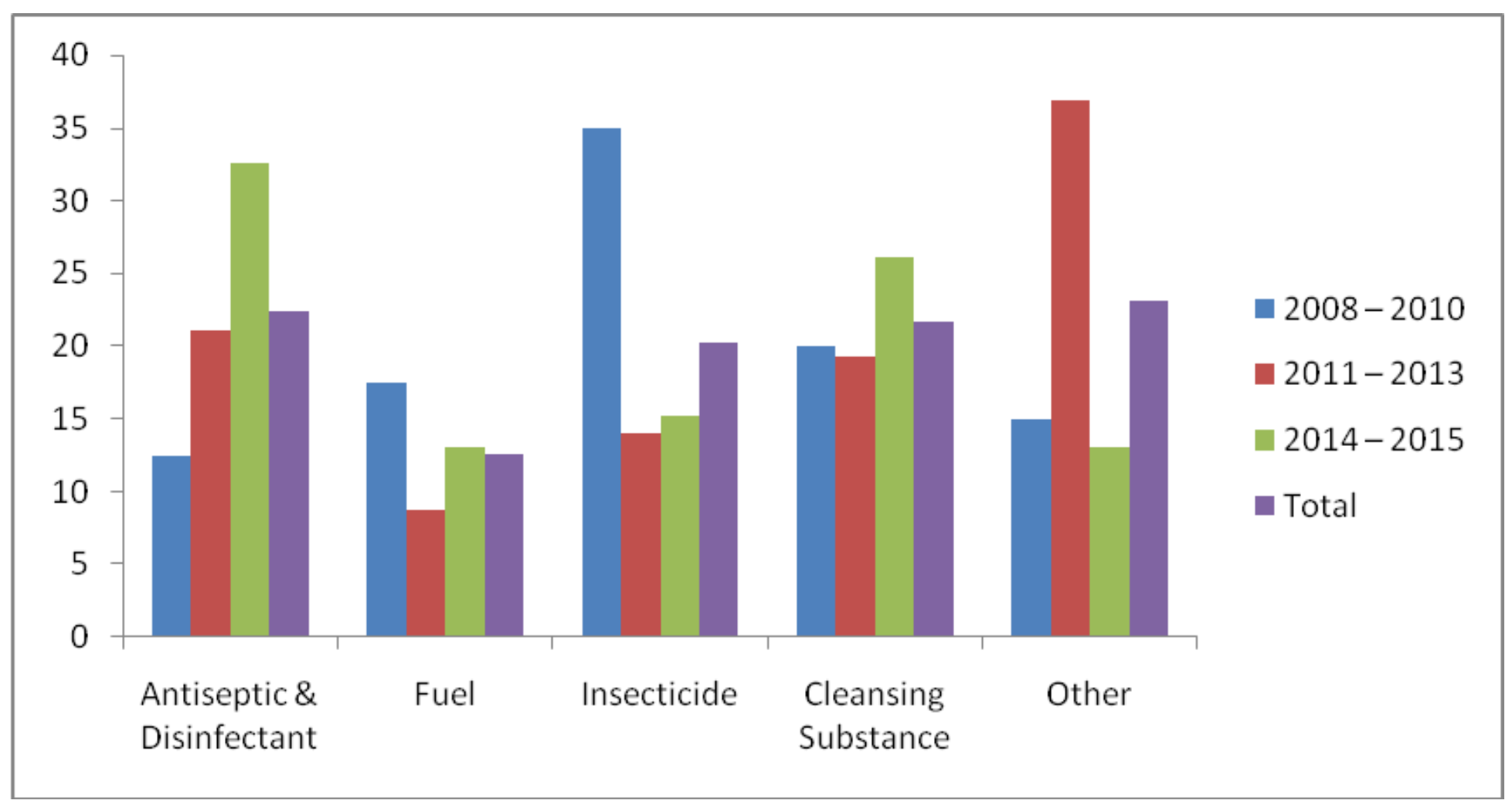

Figure 1

Frequency of poisonings and the type of poison ingested according to gender and period of poisoning 